\title{
微小粒子間の付着力測定装置の開発
}

\section{The Development of an Apparatus for Measuring the Adhesive Force between Fine Particles}

\author{
島田 泰拓 ${ }^{\mathrm{a}}$, 米澤 頼信 ${ }^{\mathrm{a}}$, 砂田 久- ${ }^{\mathrm{a}}$, 野中 隆盛 ${ }^{\mathrm{b}}$ \\ Yasuhiro SHIMADA, Yorinobu YONEZAWA, Hisakazu SUNADA, Ryusei NONAKA
}

加藤 賢三 ${ }^{\mathrm{b}}$, 森下 広 ${ }^{\mathrm{c}}$

Kenzou KATOU, Hiroshi MORISHITA

\begin{abstract}
We developed a new apparatus to measure adhesive forces between fine particles and those of fine particles on a substrate with flat surface by a direct separation method. The apparatus monitored the behavior of individual particles by a microscope with image analyzer when particles were separated from each other, and was able to measure the adhesive force with a high resolution (approximately $2 \mathrm{nN}$ ). Among the organic particles studied in the present work (corn starch, potato starch and lactose), potato starch showed the highest adhesive force, while lactose showed the lowest adhesive force on a substrates with flat surface. It was clarified that the particle diameter and the size distribution affect the adhesive force of fine particles.
\end{abstract}

Key Words : Adhesive Force, Fine Particle, Organic Particle, HPMC Capsule, Gelatin Capsule

\section{1. 緒言}

従来から粒子の付着力を定量する方法にはさまざま な手法が用いられている。間接的な方法には安息角, せん断応力, 流動化限界力, カサベリ度などの粉体層 を用いた付着力測定法がある。直接的な方法で多数 個の粒子を対象とする方法には, 遠心法 ${ }^{1.23}$, 衝撃 法1.4)などの画像処理, 統計処理を用いた付着力測定 法がある。1 個粒子を対象とする方法としては, バネ 秤などを用いて 1 個粒子を平面や他の粒子から直接分 離する力を測定する方法 ${ }^{5)}$ があるが, この手法の対象

\footnotetext{
2000 年 3 月 8 日受付

第 37 回粉体に関する討論会（1999年 10 月，北海道）にて発表 $\mathrm{a}$ 名城大学薬学部

（テ468-8503 名古屋市天白区八事山150）TEL 052-832-1781

Faculty of Pharmacy, Meijo University

(150 Yagotoyama, Tempakuku, Nagoya, 468-8503)

b 岡田精工株式会社

（テ157-0062 東京都世田谷区南烏山4-27-8） TEL 03-3308-1217

OKADA SEIKO Co., Ltd.

(4-27-8. Minamikarasuyama, Setagaya-ku, Tokyo,

157-0062)

c 有限会社エイチ・エム・アイ

（テ271-0093 松戸市小山35-2，松戸パレ ス1002）

TEL 047-363-0585

HMI Inc.

(Matudo-Paresu 1002, 35- 2 Koyama Matudo, 271-0093)
}

は $200 \mu \mathrm{m}$ 以上の大きさの粒子に限られ，しかも無機 粉体が対象であった。今回用いた微小粉体付着力測定 装置 (PAF-300, 岡田精工 (株), 東京) は $20 \mu \mathrm{m}$ 程 度の粒子でも平面一微小粒子間, 微小粒子一微小粒子 間の付着力を目視しながら直接測定することが可能な 装置である。すなわち, 微小粒子を付着させた下地, または微小粒子の凝集塊から直接目的とする粒子を引 きはがし、この時必要となるごく微小な力を測定でき る装置である。その際に, 顕微鏡や CCD カメラによ り直接目標とする粒子を選択し付着力を測定できるた め, その付着状態や分離状態と付着力との関係を知る ことができる。今回の報告では，あわせて遠心法によ る測定も行い, 本装置の付着力測定結果と比較検討を 行った。

\section{2. 試料}

試料粉体として, コーンスターチ（コーンスターチ $\mathrm{W}$, 日本食品化工 (株), 岡山), 乳糖 (Pharmatose 200M, DMV international), ポテトスターチ(精 製でんぷん，ホクレン農業協同組合連合会, 北海道) を用いた。平面一微小粒子間における付着力測定実験 では, 微粒子を付着させる下地としてスライドグラス (Micro Slide Glass, 松浪硝子工業 (株), 大阪), 平 


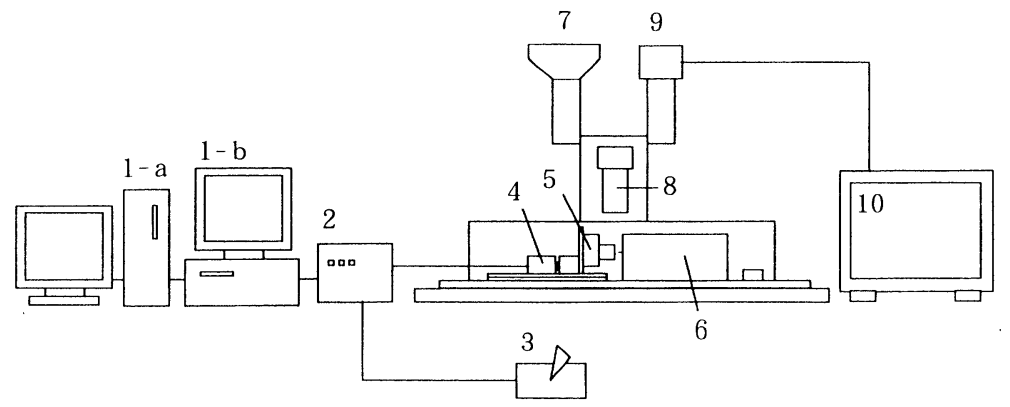

Fig. 1 Schematic diagram of apparatus for measuring adhesive force $1-$ a. Imagr analyzer 1-b. Computer of sensor unit

2. Control box of 3 -axes movable stage

3. Joystick of 3 -axes movable stage 4. Driving Motor

5. 3-axes movable stage 6. Sensor unit 7. Optical microscope

8. Stereoscope 9. CCD-video camera 10. Video monitor

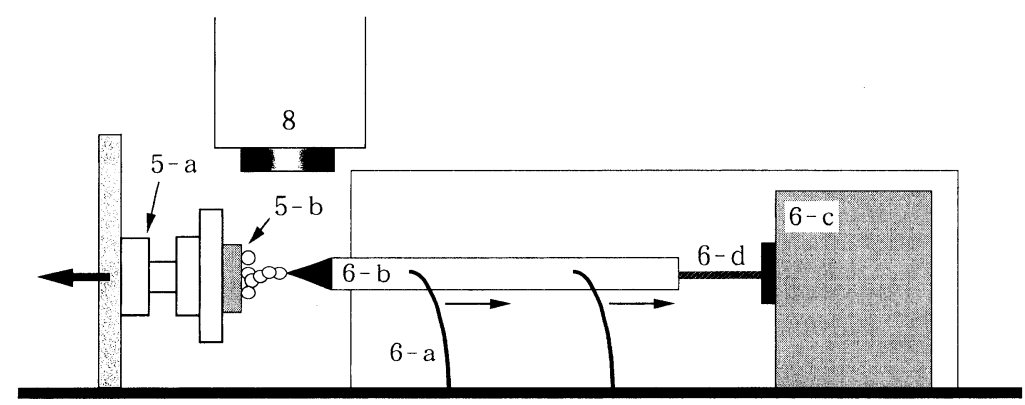

Fig. 2 Schematic diagram of sensor unit 5-a. 3-axes movable stage 5-b. Samples 6-a. Plate spring 6-b. Contact needle 6-c. Laser unit 6-d. Laser beam 8. Stereoscope

面に付着させる粉体と同素材の粉体を圧縮成形した錠 剂, 医薬分野で汎用されるゼラチンカプセル 0 号 (CLEAR Y，シオノギクオリカプス（株），奈良）を 用いた。また，比較実験として行った遠心法による測 定にも同様なゼラチンカプセル 0 号を用いた。微小粒 子一微小粒子間付着力測定の下地には, ゼラチンカプ セル 3 号, HPMC カプセル 3 号 (CLEAR, シオノギ クオリカプス（株），奈良）を用いた。

\section{3．装置および実験方法}

\section{1 粉体の基本物性の測定}

今回用いた粉体の粒子径測定には，レーザー回折・ 散乱式粒度分布測定装置 (LMS-30，（株）セイシン企 業, 東京) を用いた。粉体の形状指数は, 高速画像解 析装置（LUZEX-FS，（株）ニレコ，東京）を用いて 測定した。その際，凹凸の度合いを示す指数 $\left(\phi_{1}\right)$ と 歪みの度合いを示す指数 $\left(\phi_{2}\right)$ の 2 種類をそれぞれ Eq. (1)，Eq. (2) を用いて測定した。 $A$ は粒子の投映
像実面積， $P M$ は粒子の投影像周囲長さ， $M L$ は粒子 の投映像最大長さである。また，粉体の水分含率は示 差走查熱量天秤 (TG-DTA2000, (株) マック・サイ エンス, 神奈川）を用いて測定した。

$$
\begin{aligned}
& \phi_{1}=4 \pi A / P M^{2} \\
& \phi_{2}=4 A / \pi M L^{2}
\end{aligned}
$$

\section{2 微小粒子間付着力測定装置 (PAF-300) の概 要と操作方法}

Fig. 1 に今回の付着力測定に用いた装置の概略図 を示した。この装置は付着力を測定するセンサー部 (6)，これを制御するコンピュータ（1-b）と画像解析 装置 $(1-a)$ ，付着力測定部分をモ二ターする実体顕 微鏡（8）とビデオ装置（9）から成る。センサー部の 詳細はFig. 2 に示されているように, 試料に接触して 引きはがすための接触針（6-b）と，それに取り付け られた 2 枚の板バネ $(6-\mathrm{a})$, その後方のレーザー変 位計（6-c）により成り立っている。ステージ（5-a) 


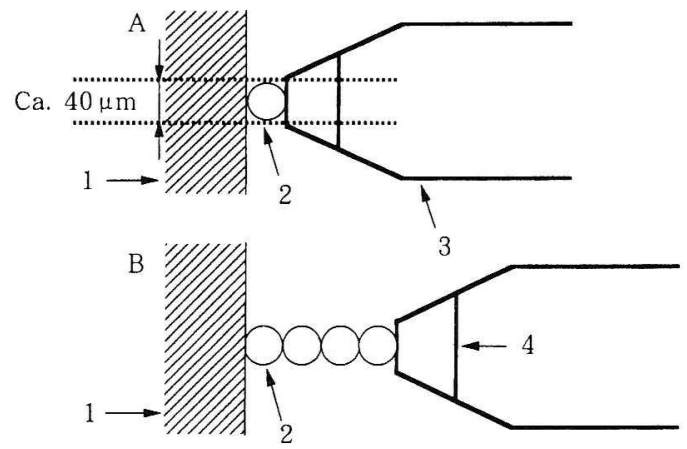

Fig. 3 Schematic figure of device measuring part A : between particle and substrate

B : between particles 1. Substrate 2. Particle 3. Contact needle 4. Diamond head

が太い矢印で示した方向に微動すると，接触針に付着 した粒子を介してサンプル下地に針が引き奇せられる ため, 板バネにストレスが生じ左に針の位置がずれ, そのずれをレーザー変位計が計測する。さらにステー ジを左に微動させると，板バネのストレスが歧子とサ ンプル下地との付着力を上まわるようになり粒子が分 離し，板バネにかかるストレスが開放される。この 時, 針の変位は最大を示し, その変位をコンピュー夕 処理により付着力に換算する。粉体を付着させる方法 として，表面にそれぞれの粉体を目開き $75 \mu \mathrm{m}$ のふ るいを通して約 $20 \mathrm{~cm}$ 上方から自由落下させて付着 させた。実験は室温 $20-23^{\circ} \mathrm{C}$, 湿度 50-55\%にコン トロールした室内において行った。平面一微小粒子間 の付着力測定に関しては Fig. 3-Aに示したように1 個粒子を平面に付着させ，接触針を表面の粒子に付着 させた後、コンピュータ制御により自動的に微小粒子

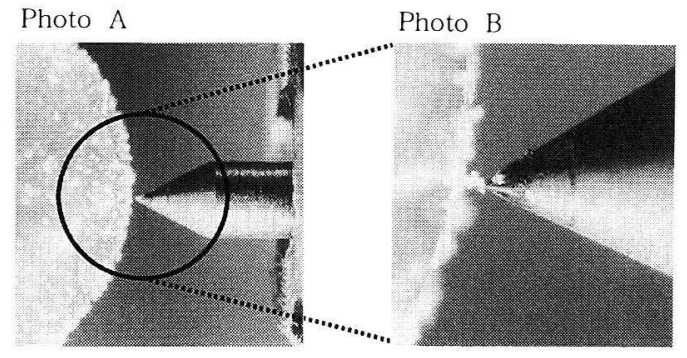

Fig. 4 Photo of contact needle, particles and capsule

A : particles adhered on capsule surface B : particles just before the separation

を平面から剥離させた。微小粒子一微小粒子間の付着 力測定に関しても同様に計測した。Fig. 3-Bの一例と して下地がカプセルの場合の写真を Fig. 4 に示した。 A は粒子をカプセル表面に付着させたものでこの桩大 図をBに示した。Bのように接触針を粒子に付着させ た後，ステージを左に約 $0.6 \mu \mathrm{m} / \mathrm{s}$ の速さでコンピ ュータ制御により移動させ、自動的に付着力を計測し た。このときに得られたデータ波形の典型的な形を Fig. 5 に示した。横軸はステージの移動距離, 縦軸は 算出した板バネにかかる力を示しており, この力が粒 子の付着力に相当する。接触針が粒子を付着表面から はぎ取る際に，4で示された最大值を経て，その後す ぐさま減少する。このときバネの自由振動により減 衰していく時の振幅の中心線と最大值との差 5 を付着 力とした。2枚の板バネに作用する力は Eq. (3)のよ うにバネ定数 $k$ と変位 $L$ の積により示されるので, $k$ を求めることができれば付着力 $F$ を算出することが できる。バネ定数 $k$ は Eq. (4) で示される ${ }^{6)}$ ので,
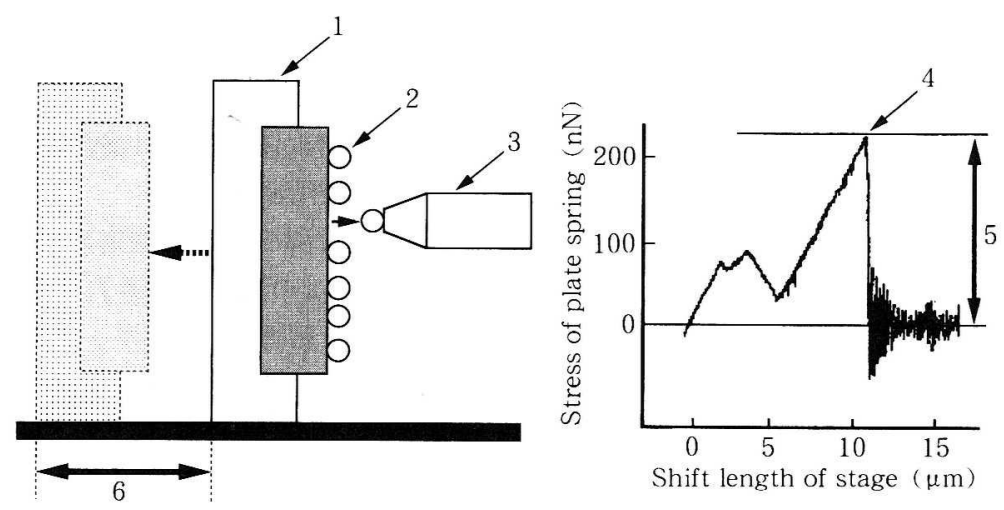

Fig. 5 Separation and adhesive force 1. Stage 2. Particle 3. Contact needle 4. Peak of adhesive force 5. Net adhesive force 6 . Shift length of stage 


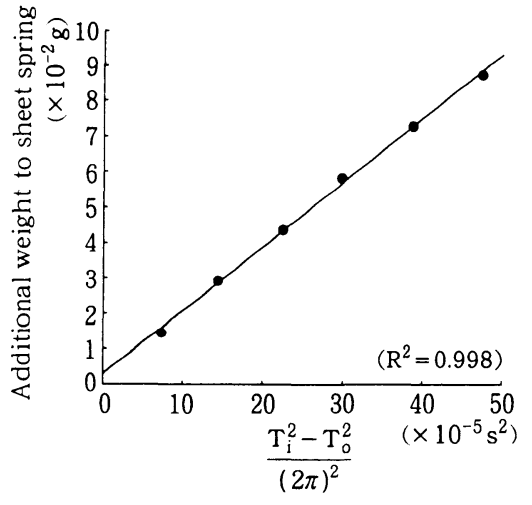

Fig. 6 Calibration of sensor unit $F=k L$

$F$; adhesive force

$L$; movement of contact needle

$\mathrm{T}_{\mathrm{o}}$; Initial characterisitic frequency of plate spring

$\mathrm{T}_{\mathrm{i}}$; Characteristic frequency of plate spring when attached additional weight

Fig. 6 のようにプロットを行うとその傾きから求める ことができる。

$$
\begin{aligned}
& F=k L \\
& k=4 \pi^{2}(\text { add.w. }-c) /\left(T_{\mathrm{i}}^{2}-T_{\mathrm{o}}^{2}\right)
\end{aligned}
$$

ただし，add.w.は板バネに追加した重りの重量, $T_{\mathrm{i}}$ はこのとき測定されたバネの固有振動数, $T_{\mathrm{o}}$ はバ ネの初期固有振動数，cは $y$ 軸切片である。Fig. 6 上 り，センサーのバネ定数 $k$ は 0.18 と算出された。ま た，この装置では粒子を水平に引っ張るため，測定に 及ぼす粉体の自重の影響をEq. (5) により確認し，垂 直方向に作用する力の影響を検討した。

$$
F_{\mathrm{g}}=4 \pi(d / 2)^{3} \rho \alpha / 3
$$

\section{3 接触針と測定粒子の接着}

平面と粒子の付着力に比較して粒子の接触針との付 着力が低い場合，接触針と粒子の間をなんらかの方法 で接着させる必要性がある。今回は，ポテトスターチ とゼラチンカプセルの付着力測定において，ポテトス ターチとゼラチンカプセルのほうが針との付着力より も高く測定され，接着剂を用いない場合には測定が不 可能であった。そのため, 粒子と接触針との間に接着 剂を用い，針に粒子を付着させた。今回の測定では， 高分子ポリマーのヒドロキシプロピルセルロース （HPC - L，（株）日本曹達, 東京）の $40 \%$ 水溶液を 接着剂として用いた。また，逆に接触針と粒子との付
着力が粒子と平面間の付着力に比へて大きい場合に は，接着する処理を行わなかった。

3. 4 平面一微小粒子間の付着力における遠心法に よる測定とPAF-300による測定の比較

遠心法により，ゼラチンカプセルに対するポテトス ターチの平均付着力 $F_{50}$ を測定した。さらに PAF300 により，ゼラチンカプセルに対するポテトスター チの平面一微小粒子間の付着力を測定した。この二つ の手法は，同じ平面之 1 個粒子の付着力を測定してい るため，比較の対象になりうる。遠心法の平均付着力 $F_{50}$ は，一定の遠心力を粒子群に作用させ， その半数 が分離する時の粒子径を求め, 計算により付着力を算 出しているので, 平均付着力 $F_{50}$ に対応する粒子径を 求めることができる。PAF-300において，測定した い粒子径は自由に選択することが可能であるが，今回 の測定では安定した測定結果が得られる $60 \mu \mathrm{m}$ 程度 の比較的大きな粒子の測定結果となった。両実験と もに空温 $20-23^{\circ} \mathrm{C}$, 湿度 50-55\% で行っておりこ の条件は比較的に液体架橋の影響が低(7)のでファン デルワールスカの影響だけを考慮の対象とし，得られ た付着力からポテトスターチの Hamaker 定数 $H$ を Eq. （6）により算出した。 $H$ は炭化水素系物質の場 合，一般に $4.0 \sim 10.0 \times 10^{-20} \mathrm{~J}$ の值を持つ之報告 ${ }^{7)}$ さ れており，得られた付着力から算出した定数がこの值 に適合するかを検討した。また付着距離 $a$ は，ファ ンデルワールスカが最大となる距離に相当し, 文献 值 ${ }^{8)}$ として $0.4 \mathrm{~nm}$ を用いた。

$$
F_{\text {vdw }}=H d / 24 a^{2}
$$

\section{4. 結果と考察}

\section{1 平面・微小粒子間の付着力測定 ${ }^{1.9-11)}$}

Table 1 に，今回用いた粉体の平均粒子径， $10 \%$ 累 積粒子径, $90 \%$ 累積粒子径, 形状指数, 水分含率の 測定結果を示した。この粉体を用いて Table 2 に，ス ライドガラスを下地にした場合のコーンスターチ, 乳 糖, ポテトスターチの付着力測定結果を示した。付着 力は乳糖, コーンスターチ，ポテトスターチの順に高 くなり，しかもポテトスターチの付着力は乳糖の付着 力に比較し約 4 倍以上であり，コーンスターチと比較 しても同様に大きな差を示した。同じくTable 2 に付 着粒子と同じ粉体を圧縮成形して錠剂を作製し，この

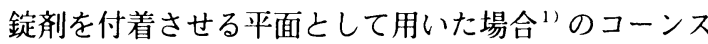
ターチ, 乳糖, ポテトスターチの付着力を示した。ス ライドガラスの場合と同様に付着力は乳糖，コーンス 
Table 1 Physical properties of the samples

\begin{tabular}{lcccccc}
\hline \multicolumn{1}{c}{ Sample } & $D_{10}(\mu \mathrm{m})$ & $D_{50}(\mu \mathrm{m})$ & $D_{90}(\mu \mathrm{m})$ & $\phi_{1}$ & $\phi_{2}$ & Water content $(\%)$ \\
\hline Corn starch & 10.1 & 18.0 & 33.6 & 0.854 & 0.701 & 12.4 \\
Potato starch & 18.2 & 34.2 & 60.3 & 0.898 & 0.722 & 14.1 \\
Lactose & 5.7 & 28.8 & 80.6 & 0.557 & 0.511 & 5.2 \\
\hline
\end{tabular}

Table 2 Adhesive force between particle and glass plate, tablet surface of same substance

\begin{tabular}{lrcc} 
& \multicolumn{3}{c}{ Adhesive force $(\mathrm{nN})$} \\
\cline { 2 - 4 } & Corn starch & Potato starch & Lactose \\
\hline Grass plate $^{\text {a) }}$ & $66.9 \pm 26.1$ & $188.8 \pm 60.7$ & $37.8 \pm 6.3$ \\
Tablet surface $^{\text {b) }}$ & $144.4 \pm 28.0$ & $161.3 \pm 29.0$ & $67.3 \pm 26.3$ \\
\hline
\end{tabular}

a) Each value represents the mean \pm S.D. $(n=5)$

b) Each value represents the mean \pm S.D. $(n=8)$

Table 3 Adhesive force between particle and particle on the gelatin capsule, HPMC capsule

\begin{tabular}{lccc}
\hline & \multicolumn{3}{c}{ Adhesive force $(\mathrm{nN})$} \\
\cline { 2 - 4 } & Corn starch & Potato starch & Lactose \\
\hline Gelatin capsule & $145.0 \pm 30.4$ & $270.8 \pm 49.9$ & $78.1 \pm 11.5$ \\
HPMC capsule & $127.1 \pm 27.6$ & $222.6 \pm 57.5$ & $79.5 \pm 24.9$ \\
\hline
\end{tabular}

Each value represents the mean \pm S.D. $(n=8)$

ターチ，ポテトスターチの順に高くなったが，下地が スライドガラスの場合ほど大きな差は示さなかった。 これらの要因として, Table1に示したように粉体の粒 子径1.10.11)，粒子形状の影響9.11. 12) が最も大きいと思 われる。粒子の形状が球に近いほど, 粒子の表面が滑 らかで凹凸が少ないほど，有効接触面積が大きくなり 粒子と平面間の平均的距離が小さくなるため, ファン デルワールスカが増大する ${ }^{11}$ と考えられる。また, 粉体固有の水分含率による影響も考えられる。特に, 異種物質間の付着力の場合にはその影響が大きくな り，水分含率が約 $5 \%$ と他の 2 種に比べて低水分で あった乳糖の付着力が, 他に比へて低く測定されたの も，水分含量が原因の一つと考えられた。なお，こ の装置における粉体の自重による影響は，仮にポテト スターチ（粒子径 $40 \mu \mathrm{m}$, 真密度 $1.48 \mathrm{~g} / \mathrm{cm}^{3}$ ) の場 合, Eq. (5) より垂直方向に $0.49 \mathrm{nN}$ と計算され, 測 定される付着力測定值の約 $1 / 1000$ となり結果にほと んど影響を与えないため, 測定誤差の範囲内として扱 った。

\section{2 微小粒子間の付着力測定}

Table 3 は, ゼラチンカプセル表面上のコーンス
ターチ，乳糖，ポテトスターチの粒子間付着力を Fig. 3-Bに示されるモデルを用いて測定した結果である。 これより, 粒子の種類が変化した場合, Table 2に示 す平面一粒子間の付着力測定と同様に明らかに差が 認められ, 乳糖, コーンスターチ, ポテトスターチの 順に付着力が高く測定された。同じくTable 3 に, HPMC カプセル表面上のコーンスターチ, 乳糖, ポ テトスターチの粒子間付着力を示した。ゼラチンカプ セルの場合と比較して，ほぼ同様な結果が得られた が, 多少の差が発生したのは以前著者らが報告 ${ }^{12)} し$ ているが, ゼラチンカプセルと HPMC カプセルの素 材, カプセルの水分含率, および帯電量の違いにより 粒子を引き付ける静電付着力 ${ }^{13)}$ に差があるためと考 えられた。

\section{3 平面一微小粒子間の付着力測定における遠心 法と本測定法との比較}

Table 4に，遠心法によるゼラチンカプセルに対す るポテトスターチの平均付着力 $F_{50}$ と, $\mathrm{PAF}-300$ に よるゼラチンカプセルに対するポテトスターチの平 面一微小粒子間の付着力測定結果を示した。この結果 から Eq. (6) を用いて Hamaker 定数を算出し，同 
Table 4 Comparison of centrifugal separetion method and PAF-300 method

\begin{tabular}{lccc}
\hline & Particle diameter & Adhesive force $\left.{ }^{\mathrm{a} a \mathrm{~b}}\right)$ & $\mathrm{H}(\mathrm{J})$ \\
\cline { 2 - 3 }$(\mu \mathrm{m})$ & $(\mathrm{nN})$ & \\
\hline $\begin{array}{l}\text { Centrifugal separetion } \\
\text { method }\end{array}$ & 34.2 & $230.7 \pm 92.3$ & $1.5 \sim 3.6 \times 10^{-20}$ \\
PAF-300 method & 62.3 & $610.0 \pm 175.8$ & $2.6 \sim 4.8 \times 10^{-20}$ \\
\hline
\end{tabular}

a) Each value represents the mean \pm S.D. $(n=3)$

b) Measuring adhesive force of the potatostarch to gelatin capsule

様にTable 4に示した。結果より, 従来から測定法が 確立している遠心法の測定結果と PAF-300における 測定結果がほぼ同様な数值を示し，遠心法において行 われた測定精度とほぼ同様な測定が PAF-300におい ても可能であることが示唆された。また, 雨法とも に炭化水素系物質の Harmaker 定数の文献值である $4.0 \sim 10.0 \times 10^{-20} \mathrm{~J}$ の範囲内もしくは近い值が得られ た。

\section{5. 結 論}

今回，粒子を直接引きはがすことにより粒子一粒子 間および粒子一平面間の付着力を測定できる装置を用 い， 3 種の有機粉体の付着力を測定した。その結果， 付着力に明らかな差を測定することができた。この装
置において粒子を引きはがす際の, 粒子の挙動を顕微 鏡および画像解析装置によりモニタリングし, 動画と して収録し， 1 個粒子の付着力を算出することができ た。今回取り扱った 3 種の有機粉体は, 乳糖, コーン スターチ, ポテトスターチの順に高い付着力が得られ た。また，スライドガラスに対する乳糖の付着性が他 の粉体に比較し, 特に低いことが明らかとなった。こ れは, 粒子径, 粒子形状および水分含率の影響がもっ とも大きいと思われるが, 粉体の帯電性も影響を与え ていると考えられた。今後, さらに異なる温度, 湿度 下での同じ粉体の付着力変化や，従来から様々に検討 されている付着力に関する式について，この装置から 得られた測定值と比較を行うことにより，さらなる検 討が可能であると考えられた。

\section{Nomenclature}

$a$ : distance of particle and particle

$A$ : actual projected area of the particle add.w. : additional weight attached to spring

$c:$ an intercept of the $y$-axis

$d$ : mean Heywood diameter of particle measured

$D_{10}: 10 \%$ diameter in cumulative distribution

$D_{50}: 50 \%$ diameter in cumulative distribution

$D_{90}: 90 \%$ diameter in cumulative distribution

$F$ : adhesive force

$F_{50}$ : mean adhesive force in the case of centrifugal separation method

$F_{\mathrm{g}}$ : force of gravity

$F_{\text {vdw }}$ : van der Waals force

$H$ : Hamaker constant

$(\mathrm{m})$
$\left(\mathrm{m}^{2}\right)$
$(\mathrm{kg})$
$(-)$

$(\mathrm{m})$

$(\mu \mathrm{m})$

$(\mu \mathrm{m})$

$(\mu \mathrm{m})$

(N) $k \quad$ : spring constant

$L$ : shift length of contact needle

$(\mathrm{N} / \mathrm{m})$

$M L$ : maximum length of projected particle image $(\mathrm{m})$

$n$ : number of sample (-)

$P M$ : diameter of circle having a circumference equivalent to the perimeter length of the projected particle image

(m)

$T_{\mathrm{i}}$ : characteristic cycle of plate spring when attached additional weight

(s)

$T_{\text {o }}$ : initial characteristic cycle of plate spring (s)

$\alpha$ : acceleration of gravity $\left(\mathrm{m} / \mathrm{s}^{2}\right)$

$\rho$ : density of particle

$\phi_{1}$ : shape index based on $\mathrm{PM}$

$\left(\mathrm{kg} / \mathrm{m}^{3}\right)$

$\phi_{2}$ : shape index based on $\mathrm{ML}$ (-)

\section{References}

1) Mizuno, M., H. Sunada, K. Iida, A. Otsuka, H. Sakashita, H. Tada and H. Kimura : "Measurement of the Adhesive Force of Fine Particles on the Tablet Surfaces and Its Removal Method", J. Pharm. Sci. Technol., Jpn., 57, 181 - 189 (1997)

2 ) Okada, J., Y. Matsuda and Y. Fukumori : "Measurement of the Adhesive Force of Pharmaceutical
Powders by Centrifugal Method. I", Yakugaku Zasshi, 89, 1539-1544 (1969)

3 ) Iida, K., A. Otsuka, K. Danjo and H. Sunada : "Measurement of the Adhesive Force between Particles and Polymer Films”, Chem. Pharm. Bull., 40, 189-192 (1992)

4) Otsuka, A., K. Iida, K. Danjo and H. Sunada: "Meas- 
urement of the Adhesive Force between Particles of Powdered Organic Substances and a Glass Substrate by Means of the Impact Separation Method. I, Effect of Temperature", Chem. Pharm. Bull., 31, 4483-4488 (1983)

5 ) Arakawa, M. and S. Yasuda: "The Measurement of Interaction Force on Microparticles”, J. Soc. Mat. Sci., Japan, 26, 858-862 (1977)

6 ) Matsumura, S., N. Kanda, T. Tomaru, H. Ishizuka and $\mathrm{K}$. Kuroda: "A measurement of the frequency dependence of the spring constant", Phys. Lett. A, 244, 4-8 (1998)

7 ) Okuyama, K., H. Masuda, K. Higashitani, M. Chikazawa and T. Kanazawa: "2ryuushikan sougosayou", J. Soc. Powder Technol., Japan, 22, 451-475 (1985)

8 ) Massimilla, L. and G. Donsi : "Cohesive Forces Between Particles of Fluid-Bed Catalysts", Powder Technology, 15, 253-260 (1976)

9 ) Otsuka, A., K. Iida, K. Danjo and H. Sunada : "Measurement of the Adhesive Force between Particles of Powdered Materials and a Glass Substrate by
Means of the Impact Separation Method. III, Effect of Particle Shape and Surface Asperity", Chem. Pharm. Bull., 36, $741-749$ (1988)

10) Shimada, Y., M. Sunada, M. Mizuno, Y. Yonezawa, H. Sunada, K. Takebayasi, M. Yokosuka and $\mathrm{H}$. Kimura: "Measurement of the Adhesive Force of Fine Particles on Tablet Surfaces and Method of Their Removal", Drug Dev. Ind. Pharm., 26, 149-158 (2000)

11) Otsuka, A., : "Adhesive Properties and Related Phenomena for Powdered Pharmaceuticals", Yakugaku Zasshi, 118 (4), 127-142 (1998)

12 ) Shimada, Y., T. Ito, Y. Yonezawa, H. Sunada, M. Yokosuka and $\mathrm{K}$. Takebayasi: "Measurement of the Adhesive Force of Contaminative Particles on the Capsule Surface and Method of Their Removal", J. Pharm. Sci. Technol., 60 (1), 35-42 (2000)

13) Kulvanich, P. and Peter J. Stewart: "An evaluation of the air stream Faraday cages in the electrostatic charge measurement of interactive drug systems", Int. J. Pharm., 36, 243-252 (1987) 